\title{
Research for industry
}

\author{
Arno de Klerk $\cdot$ Soliman Al-Khowaiter
}

Published online: 21 June 2011

(c) The Author(s) 2011. This article is published with open access at Springerlink.com

\section{Introduction}

Petrochemical production accounts for a $6 \%$ of global energy consumption. Although this seems like a small percentage, in absolute numbers it is close to $30 \mathrm{EJ}$, i.e. $3 \times 10^{19} \mathrm{~J}$. Consequently, industrial application of petrochemical research has a meaningful impact on the global economy and on the environment.

Although the justification for petrochemical research in both industry and academia is clear, one may rightfully ask: why do we need yet another journal? The answer lies in the name: Applied Petrochemical Research. There are journals dealing with the many disciplines that support petrochemical research, such as catalysis, conversion chemistry, chemical engineering and material science. There are also journals dealing with the products from petrochemical research, such as polymers, lubricants and pharmaceuticals. However, applied petrochemical research requires integration across disciplines and products, even though studies may focus on only specific aspects. Applied studies do not have the same resolution of detail as discipline specific studies, but the relevance of applied studies is immediately apparent to practitioners that want to translate the research into actual processes and products. By its

A. de Klerk $(\square)$

Department of Chemical and Materials Engineering, University of Alberta, Edmonton, AB T6G 2V4, Canada e-mail: deklerk@ualberta.ca

S. Al-Khowaiter

National Nanotechnology Research Center (NNRC),

King AbdulAziz City for Science and Technology (KACST),

P.O. Box 6086, Riyadh 11442, Saudi Arabia

e-mail: solimank@kacst.edu.sa nature, Applied Petrochemical Research is home to multiand inter-disciplinary research dealing with petrochemicals, as well as single discipline studies that are of a more applied nature.

\section{What is petrochemical research?}

It is difficult to separate petrochemical production from fuels refining. Petrochemicals are produced mainly from crude oil, either downstream from fuels refining, or integrated with fuels refining. Petrochemical products can range from large volume products such as plastics, lubricants and solvents to speciality and fine chemicals such as cosmetics, flavourants and pharmaceuticals. In most cases, the products are synthesized from a much smaller group of intermediate commodity chemicals. Based on production volume, the main commodity chemicals that are employed as building blocks are ethylene, propylene, butenes, benzene, toluene, xylenes, methanol and ethanol. Petrochemical research encompasses feedstock production, conversion processes and petrochemical products (Table 1).

\section{Topics of specific interest}

The breadth of petrochemical research that falls within the scope of Applied Petrochemical Research, makes it difficult to enumerate the topics that are of potential interest. The topics that are being highlighted are aspects of petrochemical research where we hope to stimulate specific interest and hope to encourage potential authors to consider submissions to the journal:

(a) There is considerable diversity in petrochemical production. The scope of research relevant to petrochemical 
Table 1 A selection of typical topics in petrochemical research

\begin{tabular}{lll}
\hline Feedstock production & Conversion processes & Petrochemical products \\
\hline Olefins (ethylene, propylene, butenes, etc.) & Cracking & Polymers and plastics \\
Aromatics (benzene, toluene, xylenes, etc.) & Reforming and aromatization & Synthetic rubber \\
Oxygenates (methanol, ethanol, propylene oxide, etc.) & Isomerisation & Agrochemicals \\
Paraffins ( $n$-alkanes, waxes) & Dimerization and polymerization & Lubricants \\
& Hydroprocessing & Speciality and fine chemicals \\
& Aromatic alkylation & Pharmaceuticals and health care \\
& Oxidation & Solvents \\
& & Detergents \\
\hline
\end{tabular}

production is vast and the need for up to date information to avoid duplication of effort is acute. Technology reviews of areas that are pertinent to petrochemical production are welcomed. For example, sources of propylene, ethylene polymerization technology, overview of lubricants, etc.

(b) The breadth of topics in petrochemical research naturally dilutes the research effort in any one field compared to that in fuels refining. It is not always clear whether a specific direction of investigation is viable. Although it is customary to report only on successes in research, we hope to also attract scientifically reasoned reports on failed petrochemical applications.

(c) Unlike energy applications, where non-carbon energy sources (e.g. hydroelectric and nuclear power) can be employed as alternatives to carbon-based fuels, petrochemicals are by definition based on carbon. Around $10 \%$ of current global fossil fuel (i.e. carbon) consumption is directed towards petrochemical production and most petrochemicals are produced from conventional crude oil. Sustainability is clearly an important issue and different pathways for the production of petrochemicals may have to be developed to ensure sustainability. More carbonefficient petrochemical production from crude oil, as well as petrochemical production other carbon-based feed materials (e.g. biomass, coal, waste, natural gas) is of interest.

\section{Advantages of publishing in Applied Petrochemical Research}

There are some specific advantages of publishing in Applied Petrochemical Research, which is an open access journal made possible by the generous sponsorship by the King Abdulaziz City of Science and Technology (KACST) in Saudi Arabia:

(a) The author retains copyright on the manuscript. The material may therefore be freely duplicated and distributed.

(b) The journal is provided free of charge and no subscription is needed. The readership is consequently not restricted.

(c) Publication is managed by Springer. Manuscripts are professionally typeset to the same standard as all other journals published by Springer. The journal is also automatically included in journal packages supplied to libraries, thereby ensuring wide dissemination and promotion of the work.

(d) It is an international journal. Manuscripts are subject to full peer-review and the journal is indexed by major scientific databases and search engines.

Open Access This article is distributed under the terms of the Creative Commons Attribution License which permits any use, distribution and reproduction in any medium, provided the original author(s) and source are credited. 